\title{
Technology driven organizational structure of the firm
}

\author{
René van den Brink • Pieter H. M. Ruys
}

Received: 2 October 2007 / Accepted: 3 October 2007 / Published online: 27 November 2007

(C) Springer-Verlag 2007

\begin{abstract}
We model a corporate firm with a variable internal organizational structure that adapts to various degrees of technological cooperation. The entrepreneur determines the organizational structure that maximizes profits under participation constraints. Wages are determined by an internal cooperative pay-system, constrained by external reservation wages. We show that closer cooperation between productionworkers results in a shorter organization with enhanced positional wages relative to the external benchmarks. The corporate firm is embedded in a competitive market economy that determines reservation wages and market prices. We also allow for more general technologies and provide conditions guaranteeing a finite optimal size of the firm.
\end{abstract}

Keywords Hierarchy - Organization of the firm · Cooperative production · Optimal firm size $\cdot$ Positional wages $\cdot$ Pay-system $\cdot$ Labor complementarity

JEL Classification D23 $\cdot$ J24 $\cdot$ L22

\section{Introduction}

This paper addresses the entrepreneurial and Coasian problem of determining endogenously the optimal size of a firm in a competitive market environment. It focuses on the

We thank Rob Gilles, Dolf Talman and an anonymous referee for their comments on a previous version of this paper.

R. van den Brink $(\varangle)$

Department of Econometrics, Tinbergen Institute, Free University, De Boelelaan 1105,

1081 HV Amsterdam, The Netherlands

e-mail: jrbrink@feweb.vu.nl

P. H. M. Ruys

Department of Econometrics and OR, CentER and TILEC, Tilburg University, Tilburg, The Netherlands e-mail: ruys@uvt.nl 
situation that the production technology of the firm interacts with the organization of labor in the firm. As has been observed by Rajan and Zingales (2001), an entrepreneur is at the root of most enterprizes generating economic surplus: an entrepreneur with a unique critical resource such as an idea, good customer relationships, a new tool, or a superior management technique. An organization embodies such a management technique. It exists to solve coordination problems in the presence of specialization. Recent economics literature focuses on the incentive problem to be solved by the entrepreneur. Garicano (2000) observes that, while many important insights have been obtained from this approach, a shortcoming is that the hierarchical organization forms are assumed rather than obtained from the theory. As a consequence, incentive-based theories have little to say on the impact of changes in information and communication technology on organizational design. Just as, e.g., Williamson (1967), Keren and Levhari (1979, 1983) and Bolton and Dewatripont (1994), we focus on the organizational structure of the various positions in a hierarchical firm and thus abstain from agency issues. A change of technology has an impact on the productivity of a position in the organization and thus on the positional wage within the firm. So we have to introduce a systematic wage differentiation between positions within the firm, where the firm operates in a competitive external environment. We extend Garicano's reasoning and allow also for varying degrees of cooperation in the technology. We analyze its impact on the organization of the firm, and show that closer cooperation between production workers results in a shorter organization. These results are of great help for the entrepreneur who has to make a choice from technological and organizational possibilities.

We follow the seminal paper of Alchian and Demsetz (1972) who state that production is in principle a collective effort; see also Hart and Moore (1990) and Ichiishi (1993). Any such effort is a (production) service, which is a relation between the performer and the receiver of that service. An effort will not be performed-or a service will not be rendered-unless it is supported by a contract that implements the service. This contract may be formal or informal, complete or incomplete, and may be based on monetary or cultural transaction power. That all is represented by the organizational culture of the firm. Our approach is based on the principle of firstly separating the technology from the organization and then analyzing the interaction between the two. The novelty of this paper is the analysis of the organizational structure as a function of varying degrees of cooperation in the production structure of the firm.

We first focus on the organizational structure. The organization of a firm determines tasks, competencies, and incentives for the various roles in a firm such that the expected performance of the middle management optimally supports the productivity of the front-workers, in order to maximize the firm's value added. Garicano (2000) characterizes the organization by the task design and the structure of the hierarchy. He defines task design by the scope or discretionality of production workers and problem solvers and the frequency with which they actually intervene in production; and the structure of the hierarchy by the span of control of problem solvers and the number of layers in the organization. His main results are that when matching problems with experts is costly, the optimal organization has a pyramidal shape with the production workers at the base and with vertical communication flows; reductions in the 
cost of acquiring and communicating knowledge increase the span of control and reduce the number of levels. By accepting his organizational model we may define the organizational structure as a hierarchy of teams. Since we focus on interaction between workers rather than on the cost of knowledge, we fix the span of control or team size and vary the span of interaction between workers.

The firm's organizational structure is described by a network of teams of labor positions in the firm. Each team has one manager who is connected with his or her team-members or agents by a directed coordination relation. The network of teams is a hierarchy represented by a tree. The front-positions in the firm-agents who don't manage or coordinate a team within the firm-interact with customers and thus generate the value added of the firm. These front-positions enter the firm's production function as inputs. The top-position in the firm represents the entrepreneur of the firm who sets its strategy and chooses the technical and organizational structure. The middle-management, that is the positions between the top and the front workers, facilitates the productivity of the front-workers, as problem-solvers, coordinators or managers. A middle-manager or coordinator is a principal for the other agents in the team, and translates, monitors, and adapts the various tasks and responsibilities of its subordinates in order to let them comply with the overall mission of the firm. This mission is given by the CEO or top-principal, who aims at profit maximization. ${ }^{1}$

Next, we characterize the technology by the degree of cooperation among workers. That degree varies in this paper from an additive or linear technology with substitutable workers to a Cobb-Douglas technology with complementarity among workers. In this paper we simplify matters by comparing two situations: all front-workers are either independent in production, or they are all cooperating and interdependent. ${ }^{2}$ The organization structure restricts the technological production possibilities, which have to be embedded in the hierarchical organization structure such as the one chosen here that has a uniform and fixed team size. This choice appears to be not so harmful for a linear technology as for a Cobb-Douglas technology. The linear technology is favored in the literature just because of its property allowing for a large variation in organizational structures and forms from which one may choose an optimal one. Our approach shows that there exists a friction between technology and organization. This is a fundamental problem in institutional economics.

The entrepreneurial choice of the size of organization has to be invariant for the internal distribution of income as specified by the pay-system that distributes the value added of the firm between the profit for the owner position and the different wages for the employee positions in the firm. ${ }^{3}$ We use a cooperative distribution function, which

\footnotetext{
1 Although not written down explicitly here, this mission may be reformulated to subgoals down in the firm organization and how, in the upward direction, information about production and sales is communicated and translated in operational terms for higher levels in the firm organization. See Radner (1992) for a survey about the information processing and decentralized decision making in hierarchical firms.

2 When this stylized problem has been solved, we are able to analyze more realistic and complex firms.

3 The value added or net revenue is defined to be the revenue of the firm minus the cost that are not related to the production factors in the firm. This value added is generated by the front-workers of the firm from transactions on the market. The pay-system that we propose guarantees that this value added is equal to the sum of wages and profits for all positions or production factors in the firm, in short, to the added-value of the firm.
} 
implies that all positions earn a share in the value added that can be generated by different compositions of actively occupied positions in the firm. Since the wages and profit are assigned to the positions in the firm rather than to the persons who occupy these positions, we call them positional wages and positional profit. ${ }^{4}$ We give specific attention to the permission pay-system. The endogenous determination of these positional wages is also a novelty that distinguishes our approach from the models that follow the seminal papers of, for example, Williamson (1967) and Keren and Levhari $(1979,1983)$, where the wages of the workers are fixed and independent of the firm structure. This pay-system approximates two effects. The first is the bargaining power an employee might have from firm-specific knowledge or capabilities. So persons are rewarded for their specific positional investments and own firm-specific human capital. The second is a profit-sharing effect. The pay-system does not have an effect on incentives.

An advantage of our approach is that we apply a solution concept, the permission value, which has specifically been developed for games where the players are part of some hierarchical structure. This is in line with Rajan and Zingales (1998) who consider the control of access to a productive asset of more importance than its ownership. We incorporate this idea in the model of a hierarchically structured firm as given by Williamson (1967).

Where cooperation is assumed among the firm's positions, competition among workers enters when they seek access to the various positions. We assume competitive labor markets for each level of labor. On the labor market, potential employees are offered positional wages for the various positions in the firm. By accepting an offer, an employee is admitted to a position in the organization and voluntarily subjects himself to the hierarchy of the firm, see, e.g., Coleman (1980), Rosen (1982), and Simon (1991). If some positional wage falls below the reservation wage that position will not be occupied and the entrepreneur has to revise its plan. A labor position is activated only if a worker occupies that position. The goal of the firm's CEO is to maximize profit given the workers' participation constraint. If maximal profit falls below the external reservation profit then the owner will not activate the firm. In principle, the profit maximizing owner pays a positional wage to an employee according to his or her internal productivity as determined by the pay-system. Whether the positional wage is higher than the market wage or not, depends on the performance of the labor market for that specific type of labor position.

Next, we embed the corporate firm in the neoclassical framework of a market economy, and prove existence of a general equilibrium concept that endogenizes the reservation wages and the reservation profit. The corporate market economy consists of a given number of representative firms, a finite set of consumers and a finite set of competitive markets. ${ }^{5}$ The firm demands labor and supplies the product, while the

\footnotetext{
4 The positional wage model complements the efficiency wage theory, as it combines internal norms of a firm with external benchmarks set by efficient markets.

5 This context implies that the corporate firm's outcome is marketable. The corporate firm can also be interpreted as a non-profit or public firm. In that case, the general equilibrium framework will be much more complex.
} 
consumers demand this product and supply labor. So wages and prices interact with the optimal size of firms. The firm's supply and demand is determined by the optimal level of the organization, which is the number of levels of the firm set by the entrepreneur. Market supply of products and market demand for labor is determined by multiplying the given number of firms by their size, which determines the total number of front-workers and their output. ${ }^{6}$ Assuming consumer preferences to satisfy the standard regularity conditions, aggregation of individual demand and supply yields market demand for the consumption good and market supply of labor. A corporate market equilibrium consists of an output price, a wage and a firm size, such that (i) firm size is optimal given the prices, and (ii) the prices are competitive equilibrium prices at which market supply equals market demand given the firm size. In other words, in a corporate market equilibrium the external competitive equilibrium prices are consistent with the firms' internal equilibrium (i.e., profit maximizing size). It may be noticed that this equilibrium exists if the firm size is a continuous function of prices which is the case for firms with a linear or Cobb-Douglas production technology. However, for general production technologies (even arbitrary CES technologies) there may arise discontinuities in the firms supply and demand functions, and thus non-existence of equilibrium. Finally, we show the existence of a finite optimal firm size for firms producing according to monotone production functions such that average labor productivity is (weakly) non-increasing in firm size and the pay-system satisfies three weak conditions.

The paper is organized as follows. In the next section, we introduce the model of a corporate firm with a linear and a Cobb-Douglas production technology. In Sect. 3 we show the effect of a change in technology by the firm on its organization and determine its optimal size. The corporate market economy is introduced in Sect. 4, where also existence of a corporate market equilibrium in case production takes place according to a linear or Cobb-Douglas technology is shown. In Sect. 5 we show the existence of a finite optimal firm size under more general conditions on the production technology and pay-system. Finally, in Sect. 6 we describe related literature and give some concluding remarks.

\section{The corporate firm: model assumptions}

In this section we introduce the components of the corporate firm: the organizational structure, the technological structure, the organizational level-costs, and the pay-system. The pay-system and the level-cost parameter connect the organization with the technology by identifying positional productivities. The entrepreneur of a corporate firm adapts the firm's organization to the technology and the market prices in such a way that the firm's profits are maximized and positional wages meet at least the reservation wage. The instrumental variable at the disposition of the entrepreneur is the number of levels in the organization.

\footnotetext{
6 The determination of the firm's output by an organizational variable of the firm is a novelty and needed to solve the aggregation problem in case the output are complex services.
} 
The firm's organization specifies the various positions of teams of workers within the firm and the relations connecting these teams. For any given value of the level $n=1,2, \ldots$, the firm's organization is described by a hierarchical network $\left(N_{n}, S_{n}\right)$ of teams, in which the set of nodes, $N_{n}$, represents a set of well defined roles ${ }^{7}$ or labor positions in the firm, and the structure $S_{n}: N_{n} \rightarrow 2^{N_{n}}$ represents the set of manageragent relations or coordination relations. A team is the group of laborers that are coordinated by the same manager, including this manager. So the team of manager $i \in N_{n}$ is the set $\{i\} \cup S_{n}(i) \subseteq N_{n}$. There is a unique position having no superior, called the top position, $i_{0}$, which will be occupied by the owner or CEO of the firm. Each agent has one directly superior manager, so there is no cycle in the graph. It follows that the internal organization structure $\left(N_{n}, S_{n}\right)$ has a tree structure, its root being the top-position $i_{0}$, and the end-points forming a non-empty set of positions having no agents. These end-points are referred to as the front-positions in the firm and the set of front-positions is denoted by $W_{n}=\left\{i \in N_{n} \mid S_{n}(i)=\emptyset\right\}$.

We distinguish different levels or tiers in the organization, where each position in a given level has the same distance to the top-position. Let $N_{0}=\left\{i_{0}\right\}$ represent the top-tier with the owner-position of the firm. Then, recursively we define the sets $N_{k}=N_{k-1} \cup\left\{i \in N_{n} \backslash N_{k-1} \mid i \in S_{n}(j)\right.$ for some $\left.j \in N_{k-1}\right\}$, for $k=1, \ldots, n$. So, the sets $L_{k}=N_{k} \backslash N_{k-1}, k=1, \ldots, n$, form the different hierarchical tiers in the firm. We further assume that each manager in the firm has the same number of agents. This number is called the span of control $^{8}$ and is denoted by $s$. So $\left|S_{n}(i)\right|=s$ for all $i \in M_{n}=N_{n} \backslash W_{n} .{ }^{9}$ We refer to the number of tiers $n$ as the level of the firm. In Figure 1 the organization structure of a one-level and two-level firm is illustrated for the case that the span of control, $s$, equals 2 .

So in an $n$-level firm, the number of positions equals $\left|N_{n}\right|=\sum_{k=0}^{n} s^{k}=\frac{\left(s^{n+1}-1\right)}{(s-1)}$, the number of manager positions equals $\left|M_{n}\right|=\sum_{k=0}^{n-1} s^{k}=\frac{s^{n}-1}{s-1}$, and the number of front-positions is equal to $\left|W_{n}\right|=s^{n}$, where $W_{n}$ is partitioned in $s^{n-1}$ groups of front-workers that belong to the same team.

\footnotetext{
7 The model is therefore a role assignment model as introduced by Everett and Borgatti (1991), see also Pekec and Roberts (2001).

8 Since the workers have to be coordinated, their number is not arbitrary and depends on the size of the internal organization structure. The simplifying assumption that the team size is equal for each coordinator can only be made if the workers are homogeneous and, for each tier in the firm, the coordinators are identical. Between tiers their capacities and tasks will differ. In such a firm the number of tiers completely determines the structure of the firm. Although we eventually also want to endogenously determine the team size, in this paper we assume it to be fixed as is also done in, e.g., Williamson (1967) and Rajan and Zingales (2001).

9 Given the top-tier $L_{0}=N_{0}$, the positions at some tier, $k$, of the firm are represented by $L_{k}=$ $\left\{i_{k, 1}, \ldots, i_{k, s}\right\}$, for $k=1, \ldots, n$. Denoting the top-position $i_{0}$ alternatively by $i_{0,1}$ as the first position in tier 0 , the corresponding relational structure is $S_{n}\left(i_{l, k}\right)=\left\{i_{l+1,(k-1) s+1}, \ldots, i_{l+1, k s}\right\}, l=0, \ldots, n-1$ and $k=1, \ldots, s^{l}$.
} 


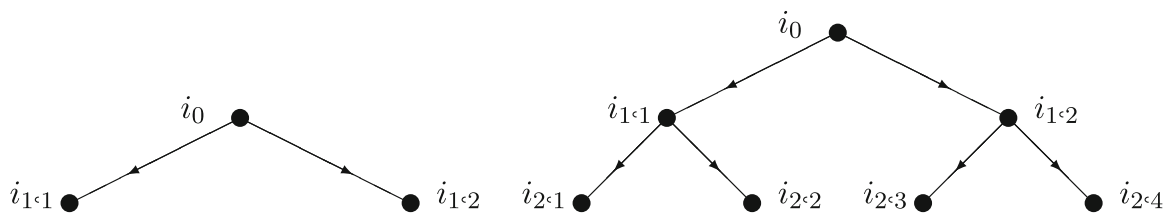

Fig. 1 A one-level and a two-level internal organization structure with span of control 2

\subsection{The technology: substitution or complementarity at the front-level}

The technological structure is represented by production outcome functions and the firm's organization. The production outcome functions specify the various production possibilities from which one to select.

We assume that the productive process in the firm is carried out by front workers who occupy the front-positions. The managers on the other positions coordinate their subordinate workers and managers yielding them access to the productive facilities. For every level $n$ of the organization, the firm's technology is therefore described by a (production) outcome function on the power set of front-positions, $f_{n}: 2^{W_{n}} \rightarrow \mathbb{R}_{+}$. The power set contains all coalitions of front-positions, where a coalition is defined as a group of front-positions who interact only with members of their group. So, for some activity all external effects are internalized in that coalition. The size of a coalition equals the span of interaction in production for a technology. In order to simplify the analysis, we assume that all front-workers are homogeneous. This means that they all have identical roles in the production process and that the production function is defined on the level-dependent 'grand coalition' of front-positions. So, the firm's outcome function can be reduced to $f_{n}:\left\{1, \ldots,\left|W_{n}\right|\right\} \rightarrow \mathbb{R}_{+}$, defined on the number of (identical) front-positions. The firm's technology now is described by a set of outcome functions, one for each possible level $\left\{f_{n} \mid n=1, \ldots, \bar{n}\right\}$, with $\bar{n}$ sufficiently large.

The outcome of the firm is sold at a competitive output price $p>0$. Thus, if all front-workers are active, that is, if all positions are occupied by workers, then the gross revenue of the firm is its outcome multiplied by the (market) price, $p f_{n}\left(\left|W_{n}\right|\right)$. Two special production technologies that gained attention in the literature are the linear and Cobb-Douglas production technologies. In a linear production outcome function, $f_{n}^{1}(\ell)=\ell$, all workers are independent and perfect substitutes, so the span of interaction is equal to one. In the Cobb-Douglas production outcome function, $f_{n}^{0}(\ell)=\left|W_{n}\right| 1^{l} 0^{\left|W_{n}\right|-\ell}$, all front-positions are indispensable and the span of interaction is equal to $\left|W_{n}\right|$. Williamson (1967) and Rajan and Zingales (2001) consider the linear technology only. The consequence for the organization is that front-positions can be split up arbitrarily in the linear case, but the 'grand coalition' has to be kept intact in the Cobb-Douglas case. Although for firms with different size the domain of the outcome function varies, in the next sections we assume that the production technology is the same for all levels of coordination, i.e., the firm produces according to a linear production technology for every size $n$ (in Sect. 5 we allow for more general firms where the technology may vary for different firm levels). 


\subsection{Level-coordination costs and value added}

Given the team structure, the only parameter determining the size of the firm is the number of team levels. Increasing the number of levels broadens the productive base of the firm but also increases the level-dependent coordination costs which are assumed to increase with the number of hierarchical levels. Examples of such costs are the translation of the central strategic mission to each consecutive operational level, or the coordination costs involved in the processing and control of level-dependent budgets and information, implying a loss of control of a coordinator over the behavior of its direct subordinates, see, e.g., Williamson (1967) or Garicano (2000). The sequence of teams decentralizes decision making at each consecutive tier and allows to decrease the complexity of the decision problem at each tier. It results, however, in certain level-dependent coordination costs. Following Williamson (1967), these coordination costs per level are stated as a percentage of final production and are represented by $(1-\alpha)$, with the parameter $\alpha$ being a compliance parameter strictly between zero and one. Coordination costs are therefore increasing in the level of the firm. Increasing the level (i.e., adding a level) in the firm structure may thus benefit the owner by increasing the scale of production, at the cost of an increase in coordination costs.

The owner of the firm gives the workers access to the production technology by allowing the workers to occupy these positions. As we have seen, if all positions are effectively occupied then a transaction value equal to $p f_{n}\left(\left|W_{n}\right|\right)$ is generated. Net revenue or value added is obtained by subtracting the level-dependent cost from this gross revenue ${ }^{10}$ yielding $p \alpha^{n} f_{n}\left(s^{n}\right)$. The compliance parameter $\alpha$ may correlate with the span of control parameter $s$, but both are given here.

\subsection{The pay-system}

Both the level-coordination parameter and the pay-system connect the organizational structure with the technological structure by identifying positional productivities. The pay-system also obeys certain external social norms that are invariant for the choice of technological and organizational structure. It is based on a cooperative game theoretic model in which teams of workers can generate a specific production value when they are coordinated by their respective managers.

The pay-system distributes the value added of a corporate firm among the worker and owner positions. We assume that all capital costs are incurred by the owner. The pay-system must be equally applicable to any specification of the organization of a firm and to any cooperative production outcome function. Since $s$ and $\alpha$ are fixed in our model, the organization structure is determined by the level $n$. So we define the positional pay-system as a function $\varphi$ that assigns a distribution of the value added to every cooperative production outcome function $f_{n}$ with internal organization structure $\left(N_{n}, S_{n}\right)$ and compliance parameter $\alpha$. We denote the reward assigned to position

\footnotetext{
10 For notational convenience we do not consider material cost that depend on the level of production. Considering these costs to have given input price $c>0$ does not change the results.
} 
$i \in N_{n}$ in a firm producing according to $f_{n}$ by $\varphi_{i}\left(f_{n}\right)$. This pay-system determines the wages that eventually are paid to the employees occupying the coordinator and front-positions. Since the rewards are assigned to and depend on the positions in the firm structure, we refer to these wages as positional wages. Similarly, we refer to the profit as positional profit.

In this section we consider the specific positional pay-system that is based on the permission value for games with a permission structure. This permission paysystem $^{11}$ distributes value added using its parts that can be generated by all subsets of front-positions $E \subseteq W_{n}$, i.e., all values $v^{f_{n}}(E)=p \alpha^{n} f_{n}(|E|)$ for $E \subseteq W_{n}$. Given these values, the dividends of subsets of front-positions are defined, recursively, by $\Delta^{f_{n}}(E)=v^{f_{n}}(E)$ if $|E|=1$, and $\Delta^{f_{n}}(E)=v^{f_{n}}(E)-\sum_{\substack{F \subset E \\ F \neq E}} \Delta^{f_{n}}(F)$, otherwise. These dividends thus can be seen as the net-productivity of the subsets $E \subseteq W_{n}$, i.e., the dividend $\Delta^{f_{n}}(E)$ represents the contribution to value added that is generated by $E$ and was not already generated by the (proper) subsets of $E$, see Harsanyi (1959).

Now, the permission pay-system $\widetilde{\varphi}$ distributes the dividend of a set of front-positions $E$ equally among the front-positions in $E$ and their superior positions. ${ }^{12}$ Note that the permission pay-system is a consistent system in the sense that it can be applied to any firm irrespective of the specific productivity of the workers, and thus it can be seen as a standard in collective wage agreements.

Three properties of positional pay-systems that are satisfied by the permission pay-system are the following. First, budget balancedness requires that the sum of wages and profit, which is the added-value of the firm, equals the value added, ${ }^{13}$ i.e., $\sum_{i \in N_{n}} \varphi_{i}\left(f_{n}\right)=p \alpha^{n} f_{n}\left(s^{n}\right)$. Second, symmetry requires that in a homogeneous firm all positions within the same coordination or worker level are assigned the same positional wage. For a homogeneous firm the symmetry of a pay-system implies that we can speak about wages assigned to levels instead of wages assigned to positions, i.e., the wage of level $k \in\{1, \ldots, n\}$ is given by $\varphi_{k}\left(f_{n}\right)=\varphi_{i}\left(f_{n}\right)$ for all $i \in N_{k}$. In particular, the wages of the worker positions at level $n$ can then be indicated by $\varphi_{n}\left(f_{n}\right)=\varphi_{i}\left(f_{n}\right)$, for all $i \in W_{n}$. Similarly, the profit of the owner position is denoted by $\varphi_{0}\left(f_{n}\right)$. Finally, vertical monotonicity requires that a supervisor does not receive a lower wage than its successors, i.e., $\varphi_{i}\left(f_{n}\right) \geq \varphi_{j}\left(f_{n}\right)$ for all $i \in M_{n}$ and $j \in S_{n}(i)$.

Next we derive the permission pay-system for the linear and for the Cobb-Douglas production technologies. The value added of a linear production firm with frontpositions $E \subseteq W_{n}$ occupied is given by

$$
v^{f_{n}^{1}}(E)=p \alpha^{n}|E| \quad \text { for all } E \subseteq W_{n},
$$

11 The permission value for games with a permission structure is studied by Gilles et al. (1992), van den Brink and Gilles (1996) and van den Brink (1997) as an adaptation of the well-known and often applied Shapley value (Shapley 1953) for cooperative games. A full characterization of the permission pay-system can be found in van den Brink (2007).

12 Formally, the payments to the firm positions are given by $\widetilde{\varphi}_{i}\left(f_{n}\right)=\sum_{\widehat{S}_{n}(i) \cap E \neq \emptyset} \underset{E \subseteq W_{n}}{ } \frac{\Delta^{f_{n}}(E)}{\left|\widehat{S}_{n}^{-1}(E)\right|}$, for all $i \in$ $N_{n}$, where for every $i \in N_{n}$ we have $j \in \widehat{S}_{n}(i)$ if and only if $i=j$ or there exists a sequence of positions $\left(h_{1}, \ldots, h_{t}\right)$ such that $h_{1}=i, h_{k+1} \in S\left(h_{k}\right)$ for all $1 \leq k \leq t-1$ and $h_{t}=j$.

13 In game theory this property is called efficiency. 
with dividends equal to $\Delta^{v^{f_{n}^{1}}}(E)=p \alpha^{n}$ if $|E|=1$, and $\Delta^{v_{n}^{1}}(E)=0$ otherwise. Profit according to the permission pay-system thus equals

$$
\widetilde{\varphi}_{0}\left(f_{n}^{1}\right)=\frac{p(\alpha s)^{n}}{n+1}
$$

while the wage assigned to front-position $i \in W_{n}$ according to the permission paysystem equals

$$
\widetilde{\varphi}_{n}\left(f_{n}^{1}\right)=\frac{p \alpha^{n}}{n+1} .
$$

For a corporate firm with a Cobb-Douglas technology, the value added is given by

$$
v^{f_{n}^{0}}(E)=\left\{\begin{array}{cl}
p(\alpha s)^{n} & \text { if } W_{n} \subseteq E \\
0 & \text { else }
\end{array}\right.
$$

so all positions in the $n$-level firm are interdependent and have to be occupied to generate a positive value added. ${ }^{14}$ The value added equals zero if at least one position is not occupied. This reflects the indispensability of the working labor inputs. In this case, the only non-zero dividend is that of the set of all workers and equals $\Delta^{v^{f_{n}^{0}}}\left(W_{n}\right)=p(\alpha s)^{n}$. According to the permission pay-system, profit and wages are equal and are given by

$$
\widetilde{\varphi}_{0}\left(f_{n}^{0}\right)=\widetilde{\varphi}_{n}\left(f_{n}^{0}\right)=\frac{p(\alpha s)^{n}}{\sum_{k=0}^{n} s^{k}}=\frac{p(\alpha s)^{n}(s-1)}{\left(s^{n+1}-1\right)} .
$$

For fixed $\alpha$ and $n$ the wage of the workers is higher as compared to the linear production case.

\subsection{The corporate firm}

The four elements $\left(\left(N_{n}, S_{n}\right), f_{n}, \alpha, \widetilde{\varphi}\right)$ introduced in this section define an $n$-level firm. A corporate firm is a set of such $n$-level firms, one for each level $n$, which describes the production technology and structure of the firm for any level $n$.

Definition 2.1 A corporate firm is a set $F=\left\{F_{n}\right\}_{n \in \mathbb{N}}$ with $F_{n}=\left(\left(N_{n}, S_{n}\right), f_{n}, \alpha, \widetilde{\varphi}\right)$ a $n$-level firm, $n \in \mathbb{N}$.

Now the central question can be answered. Which size will the entrepreneur choose for its corporate firm?

\footnotetext{
14 Note that we chose the scale parameter in the Cobb-Douglas firm so that the average labor productivity for each level $n$ is constant, and equal to that in the linear production firm.
} 


\section{The optimal size of the corporate firm}

Increasing the number of levels will increase gross revenue, but not necessarily profits. It has a positive effect on value added through the monotone outcome function. On the other hand, there is the negative effect of the level dependent efficiency cost. The owner of the firm chooses level $n$ in order to maximize profit.

Besides the unit output price $p>0$, the external organization of the firm is represented by a reservation wage $w>0$ for workers, and a reservation profit $\pi>0$ for the owner. In order for the firm to be active, the front- and coordinator positions have to be occupied by employees (i.e., front-workers and coordinators). The potential employees of a firm will accept a position in a firm with level $n$ if and only if the positional wages offered do not fall below their reservation wage.

We assume that the labor market is compartmentalized into homogeneous levels and is sufficiently differentiated to provide for each hierarchical level a competitive partial labor market. Any level may serve as a benchmark. We choose the lowest level. This assumption allows us to compare only the lowest wage offered by the firm with the reservation wage $w>0$ of the workers since the permission pay-system satisfies vertical monotonicity and thus the wage offered to a manager is always greater than or equal to the wages offered to its subordinate workers. Thus, if the workers accept the wages offered then also the managers accept the wages offered to them. ${ }^{15}$ If profit at this level is lower than the reservation profit, then the owner will not activate the firm.

Therefore, only those firm levels are supported by the external environment of the firm that are in the set $N(w, \pi, p)=N^{o}(w, p) \cap N_{o}(\pi, p)$, where $N^{o}(w, p)=\{n \in$ $\left.\mathbb{N} \mid \widetilde{\varphi}_{n}\left(f_{n}\right) \geq w\right\}$ is the set of levels that satisfy the worker participation constraint, and $N_{o}(\pi, p)=\left\{n \in \mathbb{N} \mid \widetilde{\varphi}_{0}\left(f_{n}\right) \geq \pi\right\}$ is the set of levels that satisfy the owner participation constraint. The optimal firm level $n^{*}$ is the lowest level of coordination that maximizes profit under these constraints.

Definition 3.1 The optimal firm level of a corporate firm $F$, given reservation wage $w$, reservation profit $\pi$ and output price $p$, is the level

$$
n^{*}(w, \pi, p)=\min \left\{n \in N(w, \pi, p) \mid \widetilde{\varphi}_{0}\left(f_{n}\right)=\max _{\hat{n} \in N(w, \pi, p)} \widetilde{\varphi}_{0}\left(f_{\hat{n}}\right)\right\}
$$

if there exists $n \in N(w, \pi, p)$ with $\widetilde{\varphi}_{0}\left(f_{n}\right) \geq 0$.

Note that an optimal firm level does not need to exist. For the moment we ignore the owner participation constraint. Let us first consider a linear production firm. Assume for simplicity that the level $n$ can be any non-negative real number $n \in \mathbb{R}_{+}$. The wage assigned to the front-positions as given by Eq. (2) is decreasing with the firm level $n$ (see the right picture in Fig. 2). ${ }^{16}$

Therefore, the set $N(w, 0, p)=[0, n(w)]$ is connected and bounded from above by the reservation wage level $n(w)$ defined as the firm level above which the wage of

15 We can generalize our results to a situation with different reservation wages for different levels, but for notational convenience we assume a uniform reservation wage.

${ }^{16}$ Since $\ln (\alpha)<0$ (because $\alpha<1$ ) it holds that $\frac{d \widetilde{\varphi}_{n}\left(f_{n}^{1}\right)}{d n}=\frac{p \alpha^{n}((n+1) \ln (\alpha)-1)}{(n+1)^{2}}<0$. 

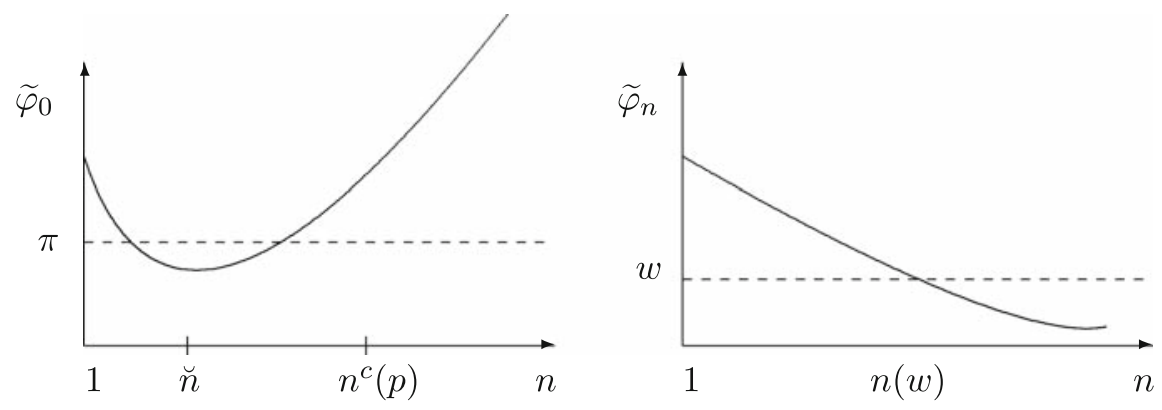

Fig. 2 Profit and wages for a linear production technology

workers is lower than their reservation wage, i.e.,

$$
n(w)=\max \left\{n \in \mathbb{R}_{+} \mid \widetilde{\varphi}_{n}\left(f_{n}\right) \geq w\right\}=\max \left\{n \in \mathbb{R}_{+} \mid \frac{p \alpha^{n}}{n+1} \geq w\right\} .
$$

The optimal level of the firm is determined by maximizing profit [see Eq. (1)] of the owner. It turns out that profit decreases to a minimum, attained at

$$
\breve{n}=\frac{1}{\ln (\alpha s)}-1
$$

and then increases monotonically (see the left picture in Fig. 2). ${ }^{17}$ This implies that from the critical level $n^{c}(p)$, being the minimal size for which profit is at least as high as profit for a firm of level 1 , there is no limit to the firm level from the point of view of the owner, and thus the owner will try to expand the firm level as high as possible due to its profit maximizing behavior. The owner, however, is restricted in this ambition by the labor market, i.e., the optimal firm level $n^{*}$ should be an element of $N(w, 0, p)=[0, n(w)]$.

Next we discuss how the optimal level $n^{*}$ looks like. If profit at the reservation wage level $n(w)$ exceeds profit at level one, i.e., if $\widetilde{\varphi}_{0}\left(f_{n(w)}^{1}\right)>\widetilde{\varphi}_{0}\left(f_{1}^{1}\right)$, then the reservation wage level $n(w)$ exceeds the critical level $n^{c}(p)$. In that case the owner will set the level of the firm equal to the reservation wage level $n(w)$ and, implicitly, will set the wage of the workers as close to their reservation wage as possible.

However, if profit at the reservation wage level $n(w)$ does not exceed profit at level one, i.e., if $\widetilde{\varphi}_{0}\left(f_{n(w)}^{1}\right) \leq \widetilde{\varphi}_{0}\left(f_{1}^{1}\right)$, then $n(w) \leq n^{c}(p)$. If wages at level one are (at least) equal to the reservation wage, i.e., if $\widetilde{\varphi}_{n}\left(f_{1}^{1}\right) \geq w$, then the firm will have only one hierarchical level and one team with the CEO as manager. If $\widetilde{\varphi}_{n}\left(f_{1}^{1}\right)<w$, the firm cannot afford the reservation wage and will not be active.

\footnotetext{
17 The first order condition for profit maximization yields $\frac{d \widetilde{\varphi}_{0}\left(f_{n}^{1}\right)}{d n}=\frac{p(\alpha s)^{n}((n+1) \ln (\alpha s)-1)}{(n+1)^{2}}=0$, so $n=$ $\frac{1}{\ln (\alpha s)}-1$. It may be noticed that $\alpha s>0$, otherwise there would be no reason to expand. For $n=\frac{1}{\ln (\alpha s)}-1$, the second order condition yields $\left.\frac{d^{2} \widetilde{\varphi}_{0}\left(f_{n}^{1}\right)}{d n^{2}}\right|_{n=\frac{1}{\ln (\alpha s)}-1}=\frac{(p \alpha s)^{n}\left(((n+1) n \ln (\alpha s))^{2}-2(n+1) \ln (\alpha s)+2\right)}{n^{3}}>0$, which yields $\breve{n}$ given by (5).
} 
Table 1 Linear production, $s=6, \alpha=0.9, p=1$

\begin{tabular}{lcc}
\hline$n$ & $\widetilde{\varphi}_{0}\left(f_{n}^{1}\right)$ & $\widetilde{\varphi}_{n}\left(f_{n}^{1}\right)$ \\
\hline 1 & 2.7 & 0.450 \\
2 & 9.7 & 0.270 \\
3 & 39.37 & 0.182 \\
4 & 170.061 & 0.131 \\
5 & 765.275 & 0.098 \\
\hline
\end{tabular}

On top of this comes the participation constraint of the owner, which requires that $\max \left\{\widetilde{\varphi}_{0}\left(f_{1}^{1}\right), \widetilde{\varphi}_{0}\left(f_{n(w)}^{1}\right)\right\} \geq \pi$. Of course, $n=0$ if $\max \left\{\widetilde{\varphi}_{0}\left(f_{1}^{1}\right), \widetilde{\varphi}_{0}\left(f_{n(w)}^{1}\right)\right\}<\pi$.

Empirical estimates of these parameters indicate that the level $\breve{n}$, for which profit attains its minimum, will probably never be attained, since $\breve{n}=\frac{1}{\ln (\alpha s)}-1 \leq 1$ if and only if $\alpha s \geq e^{\frac{1}{2}} \simeq 1.65$. Thus, if $\alpha s \geq e^{\frac{1}{2}} \simeq 1.65$ then profit of the owner attains its minimum at $\breve{n} \leq 1$ and profits are monotonically increasing in $n \geq 1$. For $s=2$ this means that $\widetilde{\varphi}_{0}$ is increasing in $n$ for $\alpha \geq \frac{1}{2} e^{\frac{1}{2}} \simeq 0.825$. For $s>2$ this is even the case for lower values of $\alpha$. Williamson (1967) argues that $\alpha$ mostly will be in the neighborhood of 0.9 . So, for a linear production firm we might expect profit to be increasing in $n$, and the level of the firm to be determined by the reservation wages of the workers.

Proposition 1 (linear production outcome functions) Consider a corporate firm with linear production outcome functions. If an optimal firm level exists and $\alpha \geq \frac{1}{2} e^{\frac{1}{2}}$, then profit is monotonically increasing in firm level $n \geq 1$, and the optimal firm level is equal to $n^{*}=n(w)$, which level is bounded above by the reservation wage of the workers.

Under the conditions of this proposition, employment in the firm is equal to $\left|N_{n(w)}\right|=\Sigma_{k=0}^{n(w)} s^{k}=\left(s^{n(w)+1}-1\right) /(s-1)($ see the end of Sect. 2.1)

As mentioned above, the condition $\alpha \geq \frac{1}{2} e^{\frac{1}{2}}$ can be weakened to $\alpha s \geq e^{\frac{1}{2}}$. If an optimal firm level exists but $\alpha s<1.65$ then the owner chooses the deepest organization $n^{*}=n(w)$ only if at that level the profit exceeds the profit of a one-level firm. Otherwise the flattest structure $n^{*}=1$ is chosen. Finally, the firm is inactive if there does not exist an optimal firm level.

Example 3.2 We first consider an example where the values for the parameters are as suggested by Williamson (1967). He argues that the normal range for $s$ is between 5 and 10. Now, let $s=6, p=1$, and $\alpha=0.9$. In Table 1 we give some values for $\widetilde{\varphi}_{0}\left(f_{n}^{1}\right)$ and $\widetilde{\varphi}_{n}\left(f_{n}^{1}\right)$.

Since $\breve{n}<1$, profit is increasing from level 1 onwards. Assuming that the firm level must be a natural number, the critical level $n^{c}(p)$ thus equals 1 . From the table it follows that if, for example, $w=\pi=0.15$ then the optimal firm level is equal to 3 , and the workers are pushed to their reservation wages.

Example 3.3 Next we give an example with level cost so high that $\alpha s<1.65$. Let $s=2, p=1$ and $\alpha=0.7$. Table 2 gives some values for $\widetilde{\varphi}_{0}\left(f_{n}^{1}\right)$ and $\widetilde{\varphi}_{n}\left(f_{n}^{1}\right)$. 
Table 2 Linear production, $s=2, \alpha=0.7, p=1$

\begin{tabular}{lll}
\hline$n$ & $\widetilde{\varphi}_{0}\left(f_{n}^{1}\right)$ & $\widetilde{\varphi}_{n}\left(f_{n}^{1}\right)$ \\
\hline 1 & 0.700 & 0.350 \\
2 & 0.653 & 0.163 \\
3 & 0.686 & 0.086 \\
4 & 0.768 & 0.048 \\
5 & 0.896 & 0.028 \\
\hline
\end{tabular}

Thus, assuming that the firm level must be a natural number, the profit of the firm is minimal for $\breve{n}=2$. The critical level equals 4 . If, for example, $w=\pi=0.15$ then the workers will only accept a position in a firm with level $n \leq 2$. In that case the owners will form the flattest hierarchical structure, and thus the firm will have one level.

If the reservation wage is low enough, for example, $w=0.03$, then the owners of the firm will push the workers to their reservation wages and set firm level equal to 4 .

The situation is different for a corporate firm with a Cobb-Douglas technology. Again assuming for simplicity that the level $n$ can be any non-negative real number $n \in \mathbb{R}_{+}$, in that case profit and wages are decreasing in the number of hierarchical levels, given the reservation wage of the lowest level. ${ }^{18}$ It follows that the owner sets firm level not higher than 1, the flattest possible structure. The workers accept the positions in the firm if and only if $\frac{p \alpha s(s-1)}{s^{2}-1} \geq w$.

Proposition 2 (Cobb-Douglas production outcome functions) Consider a corporate firm with Cobb-Douglas production outcome functions. If an optimal firm level exists, it is equal to $n^{*}=1$.

The technological requirement of interdependence of all positions in $W_{n}$ is supported by the organizational structure of a single team with size $s+1=\left|W_{n}\right|+1$. In this case of full complementarity between front-positions, employment in the firm is equal to $\left|N_{n^{*}}\right|=s+1$.

Example 3.4 Let $p=1, \alpha=0.7$, and $s=2$. In Table 3 we give some values for $\widetilde{\varphi}_{0}\left(f_{n}^{0}\right)$ and $\widetilde{\varphi}_{n}\left(f_{n}^{0}\right)$. Clearly, profit is decreasing in firm level, and a finite critical level does not exist.

\section{Demand and supply in a corporate market economy}

In the previous section output price, reservation wage and reservation profit were exogenously given. In this section we endogenously determine the reservation and output prices by a new equilibrium concept. We define a market economy in which supply of consumer goods and demand for labor is set by a representative corporate

\footnotetext{
18 Since $\ln (\alpha)<0$ (i.e., $\alpha<1$ ) and $\ln (\alpha s)>0$ (i.e., $\alpha s>1$ ), it holds that $\frac{d \widetilde{\varphi}_{0}\left(f_{n}^{0}\right)}{d n}=$ $\frac{p(\alpha s)^{n}(s-1)\left(s^{n+1} \ln (\alpha)-\ln (\alpha s)\right)}{\left(s^{n+1}-1\right)^{2}}<0$.
} 
Table 3 Cobb-Douglas production, $s=2$, $\alpha=0.7, p=1$

\begin{tabular}{ll}
\hline$n$ & $\widetilde{\varphi}_{0}\left(f_{n}^{0}\right)=\widetilde{\varphi}_{n}\left(f_{n}^{0}\right)$ \\
\hline 1 & 0.467 \\
2 & 0.280 \\
3 & 0.183 \\
4 & 0.124 \\
5 & 0.085 \\
$\infty$ & \\
\hline
\end{tabular}

firm as defined in the previous sections. Consider the triple $E=(F, \mathcal{C}, \mathcal{M})$, with a representative corporate firm $F$, a finite set of consumers ${ }^{19} \mathcal{C}$ and a finite set of competitive markets $\mathcal{M}$. Such a triple $E$ is called a corporate market economy.

The internal equilibrium of the corporate firm is determined by the optimal level of its organization, which is a function $n: \mathbb{R}_{+}^{3} \rightarrow \mathbb{R}$, where $n(w, \pi, p)$ is the optimal firm level as given in Definition 3.1 for the reservation wage $w$, the reservation profit $\pi$ and the output price $p$. In this section, the reservation prices in the previous sections are replaced by market prices, i.e., the reservation wage is determined by the market wage, the reservation profit is determined by the rate of return on capital and the output price is determined by the market price of the consumption good.

From Sect. 2.1 we obtain the demand for labor, $d_{l}$, and the supply of commodities, $s_{c}$, of the corporate firm as functions $d_{l}(w, \pi, p)=\frac{s^{n(w, \pi, p)+1}-1}{s-1}-1$ and $s_{c}(w, \pi, p)=$ $(\alpha s)^{n(w, \pi, p)}$, for any triple of market prices $w, \pi$ and $p$. The capital needed for each active firm is equal to 1 . Market demand and supply is determined by assuming that all firms are identical. So the firm is a representative firm in the industry, which may consist of more than one firm. The number of firms is fixed-determined by the capital available in the market-but not their size. Assuming market supply of capital to be inelastic and given by $\bar{k} \in \mathbb{N}$, the number of firms on the market is then equal to $m=\bar{k}$. Assuming that the rate of return on capital $\pi$ is small enough to have no impact on the decision by the owner to activate the firm, then only the relative prices between $p$ and $w$ matter.

Given an arbitrary pair of prices $p$ and $w$ we can determine the optimal size $n(w, p)$ of the firm by maximizing positional profit (with value added evaluated at market price $p$ ) under the worker-participation constraint (determined by market wage $w$ ) as done before. Market supply of the consumption good and market demand for labor then are given by $S_{c}(w, p)=m s^{n(w, p)}$, respectively, $D_{l}(w, p)=m\left(\frac{s^{(n(w, p)+1)}}{s-1}-1\right)$.

The consumer side of the market consists of a set of consumers $\mathcal{C}$, each consumer $i \in \mathcal{C}$ having an initial endowment $\bar{c}_{i} \in \mathbb{R}_{+}$of the consumption good, $\bar{l}_{i} \in \mathbb{R}_{+}$units of time to spend as leisure or labor supply in a firm, and preferences over leisure and the consumption good represented by a utility function $u^{i}: \mathbb{R}_{+}^{2} \rightarrow \mathbb{R}$. Assuming consumer preferences to satisfy the standard regularity conditions, this yields market

19 Since in this paper the household is not incorporated, the neoclassical concept of a consumer is used. For the definition of an incorporated household see Ruys et al. (2000). 
demand for the consumption good and market supply of labor as functions of $w$ and $p$. That determines market demand of the consumption good and market supply of labor, $D_{c}(w, p)$ and $S_{l}(w, p)$.

Confronting market supply and market demand, there may exist equilibrium prices $w^{*}$ and $p^{*}$, defined as follows.

Definition 4.1 A corporate equilibrium in a corporate market economy $E$ is a pair of prices $(w, p)$ and a firm level $n$, such that:

1. The firm level $n$ is the optimal firm level given prices $(w, p)$, and

2. The prices $w, p$ are competitive equilibrium prices at which market supply equals market demand given firm level $n$.

Ruys and van den Brink (1999) show that given the standard regularity assumptions on the set of consumers, a corporate market equilibrium exists if $n$ is continuous in prices. ${ }^{20}$ For a firm with a linear production technology and $\alpha s \geq e^{\frac{1}{2}}$ a corporate market equilibrium thus exists since optimal firm level $n$ is continuous in $w$ and $p$.

Determining equilibrium prices in case the production technology is a CobbDouglas technology we only have to consider firm level $n=1$ since that is the optimal size for an active firm for all prices. In that case it is obvious that $n$ is continuous in $p$ and $w$.

In both cases, if positional profit is positive at the equilibrium output price and $\widetilde{\varphi}_{n}\left(f_{n}\right)$ exceeds the equilibrium wage at $n=1$, then these equilibrium prices are also corporate market equilibrium prices, and the optimal firm level is the firm level in the corporate market equilibrium. Otherwise, the firm level in a corporate market equilibrium equals $n=0$, and its prices are too low to activate the workers.

Proposition 3 In a corporate market economy $E=(F, \mathcal{C}, \mathcal{M})$, where the technology of the corporate firm is given by linear production outcome functions (with $\alpha \mathrm{s} \geq$ $e^{\frac{1}{2}}$ ), or Cobb-Douglas production outcome functions (with constant average labor productivity), the optimal firm level $n^{*}$ is continuous in prices $p$ and $w$. Consequently, under these conditions a corporate market equilibrium exists.

\section{Existence of a regular corporate firm}

In the previous sections we discussed a corporate firm with linear and Cobb-Douglas technologies. We finally discuss a general corporate firm where the production functions may be of a different type and even may vary across levels. We do require the production outcome function to be monotone meaning that $f(k) \leq f(l)$ if $k \leq l$. An important subclass of monotone outcome functions is the class of supermodular outcome functions (see, e.g., Milgrom and Roberts 1994) which exhibit increasing scale returns in the sense that they favor producing with larger sets of front-workers.

\footnotetext{
20 Since high reservation wages will only support small firm level it holds that $n(w, p) \rightarrow 0$ if $\frac{w}{p} \rightarrow \infty$. On the other hand, low reservation wages result in large firm level since positional return on capital is increasing in $n$ for large enough $n$, and thus $n(w, p) \rightarrow \infty$ if $\frac{w}{p} \rightarrow 0$.
} 

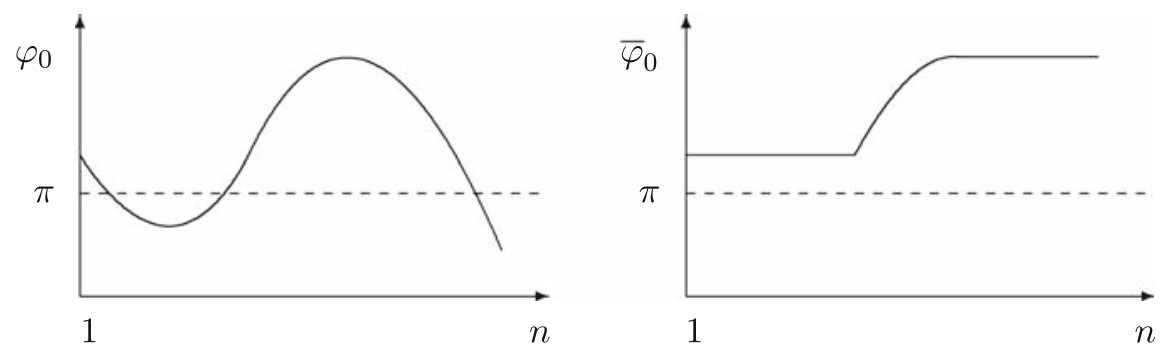

Fig. 3 Profit $\varphi_{0}$ and level dependent-profit $\bar{\varphi}_{0}$ for the owner as function of firm level

Moreover, we assume that nothing is produced if no worker is providing any labor input, i.e., $f(0)=0$. Production functions satisfying these two conditions are called regular.

In the linear and Cobb-Douglas firm considered in the previous sections, average labor productivity was constant over different levels $n$. Here we assume the weaker requirement that average labor productivity in the corporate firm with variable size is weaklynon-increasing meaning that there is a firm level $\tilde{n}$ satisfying that the production technologies in the different levels $n \geq \tilde{n}$ are such that average labor productivity is non-increasing from level $\tilde{n}$, i.e., $f_{n+1}\left(s^{n+1}\right) \leq s f_{n}\left(s^{n}\right)$ for all $n \geq \tilde{n} .^{21}$

With respect to the positional pay-system we require only that it obeys the three properties of budget balancedness, symmetry and vertical monotonicity which reflect certain economic or social norms that are considered invariant for the corporate firms in society. Positional pay-systems that satisfy these three properties are also called regular. A regular corporate firm has a regular production function and a regular pay-system. We say that a regular corporate firm exists if it has a finite size.

Suppose that the owner can choose a firm level between 1 and $n$ without any constraints. In that case the maximal profit equals $\bar{\varphi}_{0}(n)=\max \left\{\varphi_{0}\left(f_{\bar{n}}\right) \mid \bar{n} \in\{1, \ldots, n\}\right\}$ with $\bar{\varphi}_{0}(0)=0$. Thus, by $\bar{\varphi}_{0}$ we have written profit as a non-decreasing function of maximal possible firm level $n$. We call $\bar{\varphi}_{0}$ the level-dependent profit function, see Fig. 3 (in the figures we again assume for simplicity that the level $n$ can be any non-negative real number $n \in \mathbb{R}_{+}$).

In general, the set of levels that can be supported by the external environment $N(w, \pi, p)$ can be empty, disconnected or unbounded. Although we cannot characterize the organization structure without specifying the production technology, we can show that an optimal firm level exists.

Proposition 4 (existence of a finite optimal firm level) For every corporate firm $F$ with a regular production outcome function with weakly non-increasing average labor productivity and regular pay-system, for every triple of prices $(w, \pi, p)$, the set $N(w, \pi, p)$ of firm levels that are supported by the external environment is bounded. Consequently, under these conditions a finite optimal firm level exists.

\footnotetext{
21 This is a weaker version of non-increasing average labor productivity which requires that average labor productivity is immediately non-increasing from the first level.
} 

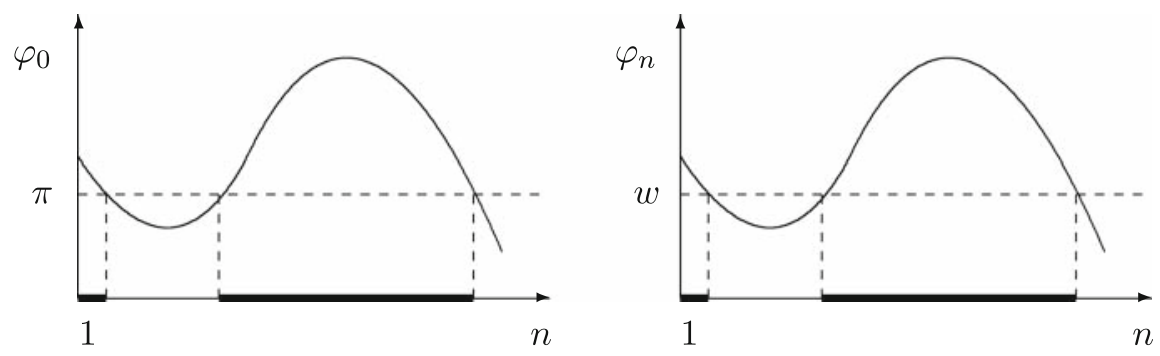

Fig. $4 N(w, \pi, p) \neq \emptyset$ but disconnected
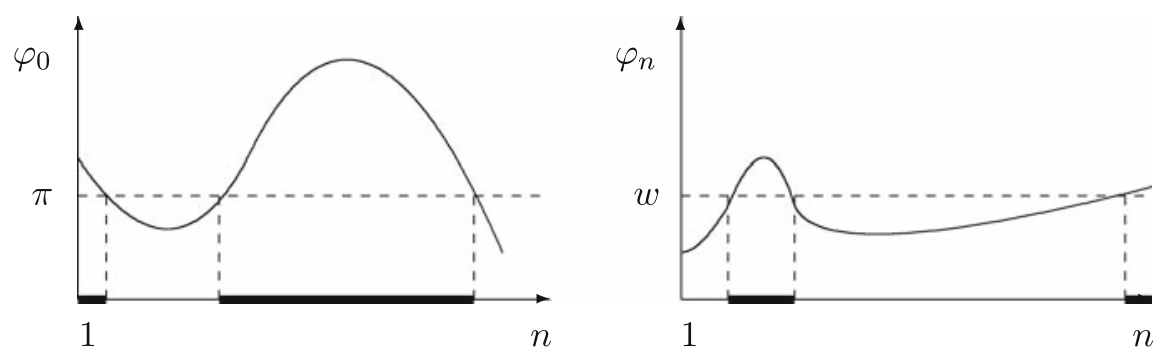

Fig. $5 N(w, \pi, p)=\emptyset$

Proof First, suppose that average labor productivity is non-increasing in firm level $n \geq 0$. Then there exists a constant $c \in \mathbb{R}_{+}$such that $f_{n}\left(s^{n}\right) \leq c s^{n}$, and thus total value added of a firm with level $n$ satisfies $p \alpha^{n} f_{n}\left(s^{n}\right) \leq p c(\alpha s)^{n}$. Since the number of positions in an $n$ level firm equals $\left|N_{n}\right|=\frac{s^{n+1}-1}{s-1}$, efficiency, vertical monotonicity and symmetry of the pay-system $\varphi$ imply that $\varphi_{n}\left(f_{n}\right) \leq \frac{p \alpha^{n} f_{n}\left(s^{n}\right)}{\left|N_{n}\right|} \leq \frac{p c(\alpha s)^{n}(s-1)}{s^{n+1}-1}=$ $\frac{p c \alpha^{n}\left(s^{n+1}-s^{n}\right)}{s^{n+1}-1} \leq p c \alpha^{n}$. So, for $\alpha<1$ it holds that $\lim _{n \rightarrow \infty} \varphi_{n}\left(f_{n}\right)=0$. But then $\left\{n \stackrel{s^{n+1}}{\in} \mid \varphi_{n}\left(\bar{f}_{n}\right) \geq w\right\}$ is bounded for $w>0$, and so is $N(w, \pi, p) \subseteq\{n \in \mathbb{N} \mid$ $\left.\varphi_{n}\left(f_{n}\right) \geq w\right\}$.

Next, suppose that there exists a $\tilde{n} \in \mathbb{N}$ such that average labor productivity is non-increasing in firm size $n \geq \tilde{n}$. Then there exists a constant $c \in \mathbb{R}_{+}$such that for $n \geq \tilde{n}$, it holds that $f_{n}\left(s^{n}\right)-f_{\tilde{n}}\left(s^{\tilde{n}}\right) \leq c s^{n-\tilde{n}}$, and thus for $\alpha<1$ we have $p \alpha^{n} f_{n}\left(s^{n}\right)-p \alpha^{\tilde{n}} f_{\tilde{n}}\left(s^{\tilde{n}}\right) \leq p \alpha^{n}\left(f_{n}\left(s^{n}\right)-f_{\tilde{n}}\left(s^{\tilde{n}}\right)\right) \leq p \alpha^{n} c s^{n-\tilde{n}}=\frac{p c(\alpha s)^{n}}{s^{\tilde{n}}}$. Then $\varphi_{n}\left(f_{n}\right) \leq \frac{p \alpha^{n} f_{n}\left(s^{n}\right)}{\left|N_{n}\right|} \leq \frac{p \alpha^{\tilde{n}} f_{\tilde{n}}\left(s^{\tilde{n}}\right)(s-1)}{s^{n+1}-1}+\frac{\left(p \alpha^{n} f_{n}\left(s^{n}\right)-p \alpha^{\tilde{n}} f_{\tilde{n}}\left(s^{\tilde{n}}\right)\right)(s-1)}{s^{n+1}-1} \leq \frac{p \alpha^{\tilde{n}} f_{\tilde{n}}\left(s^{\tilde{n}}\right)(s-1)}{s^{n+1}-1}+$ $\frac{p c \alpha^{n}\left(s^{n+1}-s^{n}\right)}{s^{\tilde{n}}\left(s^{n+1}-1\right)} \leq \frac{p \alpha^{\tilde{n}} f_{\tilde{n}}\left(s^{\tilde{n}}\right)(s-1)}{s^{n+1}-1}+\frac{p c \alpha^{n}}{s^{\tilde{n}}}$. So, for $\alpha<1$ it holds that $\lim _{n \rightarrow \infty} \varphi_{n}\left(f_{n}\right)=0$, and thus $\left\{n \in \mathbb{N} \mid \varphi_{n}\left(f_{n}\right) \geq w\right\}$ is bounded for $w>0$, and so is $N(w, \pi, p)$.

This immediately yields that the optimal firm level is finite.

Note that without a finite optimal firm level our model would not be suitable. In Proposition 4 we stated conditions under which the set $N(w, \pi, p)$ is bounded. However, it can still be disconnected (see Fig. 4) or empty (see Fig. 5).

In Sect. 3 we discussed two production technologies for which a positive optimal level exists. For firms with supermodular production outcome functions and the 
permission pay-system, sufficient conditions for the existence of a positive optimal level in $N(w, \pi, p)$ follow from the following proposition.

Proposition 5 Let $F$ be a corporate firm with the permission pay-system $\widetilde{\varphi}$ and supermodular production outcome functions $\left\{f_{n} \mid n \in \mathbb{N}\right\}$. If productivity meets reservation prices in the sense that $\frac{v^{f_{1}}\left(W_{1}\right)}{2 s} \geq w$ and $\frac{v^{f_{1}}\left(W_{1}\right)}{s+1} \geq \pi$ for every $w, \pi, p>0$, then the set $N(w, \pi, p)$ is non-empty.

Proof In van den Brink (2007) it is shown that for supermodular outcome functions with identical workers it holds that $1 \leq \frac{\widetilde{\varphi}_{i}\left(f_{n}\right)}{\widetilde{\varphi}_{j}\left(f_{n}\right)} \leq s$ for $i \in M_{n}, j \in S_{n}(i), n \in \mathbb{N}$. Applying this result to such a firm with size $n=1$ yields

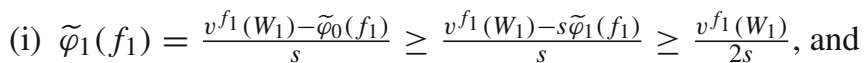

(ii) $\widetilde{\varphi}_{0}\left(f_{1}\right)=v^{f_{1}}\left(W_{1}\right)-s \widetilde{\varphi}_{n}\left(f_{1}\right) \geq v^{f_{1}}\left(W_{1}\right)-s \widetilde{\varphi}_{0}\left(f_{1}\right) \geq \frac{v^{f_{1}\left(W_{1}\right)}}{s+1}$.

Clearly, the existence of a corporate market equilibrium in this more general setting is not guaranteed because of the possible discontinuity in the labor demand and consumption good supply.

\section{Concluding remarks}

In this paper we presented a model that endogenously determines the optimal number of levels of a hierarchically structured firm with fixed team size. We have shown the effect of a varying technological structure on a rather inflexible organizational structure. Necessary for solving this problem — and one of the main novelties in this paperis the use of a cooperative pay-system, which determines positional wages that may be higher than reservation wages. This phenomenon also appears in efficiency wage theory as discussed by, e.g., Stiglitz (1976), Akerlof (1984) and Yellen (1984). However, the reason why wages can be higher than reservation wages is different. According to efficiency wage theory, laborers should be paid a rent on their equilibrium wage in order to stimulate them to put full effort in production and prevent them from shirking. In our model positional wages are possibly higher than reservation wages because of the productivity gains from cooperation reached by the team structure of the organization. How much positional wages exceed reservation wages, that is, the positional rent, also depends on other features of the market and the production technologies, such as the complementarity of labor inputs and the existence and the performance of appropriate markets. It is evident that, in order to analyze the effects of technological change, we cannot restrict ourselves just to linear production technologies as has been done by, e.g., Williamson (1967), Qian (1994) and Rajan and Zingales (2001).

The type of authority in our paper is similar to that of Rajan and Zingales (1998) who put the control of access to a productive asset as a central feature of authority. This in contrast to the literature on incomplete contracts which explains the distribution of residual rights concerning the control over non-contractable assets and thus puts ownership of assets central, see, e.g., Grossman and Hart (1986), Hart and Moore (1990, 1999), and Maskin and Tirole (1999). The relation between asset 
ownership and relational contracts is studied in Baker et al. (2002). In van den Brink and Gilles (2003) also hierarchical organizations are considered but they look at 'what game is played' within a hierarchy where superiors have the power to veto their subordinates.

In Sects. 2, 3 and 4 we have analyzed two types of corporate firms, both adapting the permission pay-system and both endowed with a constant elasticity of substitution (CES) production technology: the linear and Cobb-Douglas production technologies. These are two extreme benchmark cases with perfectly substitutable labor inputs in the linear production technology and indispensable labor inputs in the Cobb-Douglas technology. We have seen that the difference between profit and worker wages in the linear technology firm is higher than in the Cobb-Douglas firm (where they are equal). The reason is that the organizational structure does not fit with the technological structure. The fixed size of a team partitions the set of front-positions, which splitting up harms the productivity of the front-workers. As a consequence, the CobbDouglas firm will have at most one team and thus one level. In the corporate firm with linear technology, for reasonable values of the compliance parameter $\alpha$, the firm will have many teams and its deepest firm level restricted by the reservation wage of workers.

The shift from a deep to a flat organization depends also on the front-positions complementarity parameter. Formally, a homogeneous constant elasticity of substitution (or shortly CES) production outcome function for firm level $n$ is a function of the type $f_{n}^{\rho}:\left\{1, \ldots, s^{n}\right\} \rightarrow \mathbb{R}_{+}$given by ${ }^{22} f_{n}^{\rho}(k)=\gamma^{f_{n}^{\rho}}(k)^{\frac{1}{\rho}}, 0<\rho \leq 1$. We require $\rho$ to be positive in order to have a monotone production outcome function. So, a linear production outcome function corresponds to $\rho=1$, and a Cobb-Douglas production outcome function corresponds to $\rho \rightarrow 0$. For an intermediate degree of complementarity $\rho$, the profit decreases with firm level to a minimum, attained at $\breve{n}$, and then increases. The value of $\breve{n}$ [and thus the critical level $n^{c}(p)$ ] increases with complementarity (i.e., decreases with $\rho$ ). In the extreme case of a Cobb-Douglas production technology this critical level is infinite. Moreover, for fixed $\alpha$ and $n$ the position-wage of a worker lies between the low position-wage in the linear production firm with a deep organization, and the high position-wage in the Cobb-Douglas firm with a flat organization. $^{23}$

We also can explain a shift in the technology of a given corporate firm. Consider the army. Its technology was clearly linear in the past, with a deep organizational structure. The technological innovations have shifted the technology to a mixed linear and Cobb-Douglas type, changing the army to a flatter organization with more equal and higher wages. A more realistic representation of a firm's production technologywith intervals of complementary labor representing teams on the same level-falls outside the scope of analysis presented in this study.

\footnotetext{
22 A heterogeneous outcome function is a CES production outcome function with $m$ inputs if it is given by $f(x)=\gamma\left(\sum_{i=1}^{m}\left(x_{i}\right)^{\rho}\right)^{\frac{1}{\rho}}, x \in \mathbb{R}^{m}, \gamma \in \mathbb{R}, \rho \in(-\infty, 1]$.

23 So, for high enough substitutability of the labor inputs the optimal firm level is determined by the reservation wage level. Increasing complementarity will continuously decrease this reservation wage level up to a certain degree of complementarity, after which a further increase in complementarity makes optimal firm level discontinuously 'jump' to 1 .
} 
Assuming that production processes in innovative industries usually use more complementary labor, our conclusion that such an increase in complementarity leads to flatter hierarchies is in line with Teece (1996) who studies the relation between firm structure and innovation and concludes that firms strongly depending on innovation have correspondingly flatter hierarchies.

Allowing other CES-production technologies has consequences for the existence of a corporate equilibrium. For intermediate cases of workers complementarity, corporate market equilibrium prices need not exist since optimal firm level $n$ may be discontinuous in $w$. This discontinuity occurs if positional profit of a firm with maximal level that can be supported by the equilibrium wage is lower than the return on capital of a firm with level equal to 1 . In the left picture of Fig. 2 this is illustrated by a possible jump in firm level from 1 to $n^{c}(p)$.

There are several directions for further research. In this paper we studied a static model of firm formation. Similar as done here it can be shown that for CES-production technologies not too far from the linear or Cobb-Douglas technologies, a corporate equilibrium exists, but for intermediary degrees of complementarity an equilibrium might not exist. We can develop this static model in a dynamic one, which explains the evolution of the firm. Then not only firm size changes over time, but also the production technology may change. Based on the insights obtained in this paper we conjecture that in a dynamic setting, where a firm evolves from a traditional linear technology firm to higher levels of complementarity, the firm grows into a situation in which no equilibrium exists. Eventually, however, at a high enough complementarity level, existence of equilibrium is again guaranteed. The reason for this temporary disequilibrium is that, for intermediate degrees of complementarity, a firm is only profitable if it has some minimal size, which creates 'jumps' in the firm's supply and demand functions.

The permission pay-system introduced here may be replaced by other positional pay-systems. We already mentioned in Sect. 5 that existence of a finite optimal firm level holds for all pay-systems satisfying efficiency, vertical monotonicity and symmetry. Other examples of pay-systems satisfying these properties are the egalitarian pay-system (which assigns the same wage to each employee position which is equal to the profit assigned to the owner position), and every convex combination of this egalitarian pay-system and the permission pay-system. ${ }^{24}$ The varying technology in the firm induces changes in positional productivity and therefore in positional wages. So we cannot content ourselves with fixed wages. But we need a fixed wage or pay-system to compare the consecutive situations of the firm.

Further, it is relevant to know how strong both in the short run and in the long run the internal cooperative forces are relative to the external competitive forces. The basic idea is that cooperation improves productivity sufficiently such that the firm can afford a labor cost above the reservation wage of labor at the lowest level. Or, said in another way, unschooled and unemployed labor can be made more productive by and employable in a firm with an adequate hierarchical internal organization. The friction between the internal cooperative behavior and the external competitive behavior

24 In the context of cooperative TU-games, convex combinations of egalitarian wage systems and Shapley value are considered in Joosten (1996). 
is solved by accepting some imperfections in the labor markets and some hold up features in human resource management. Baron and Kreps (1999) observe that the Human Resource systems of successful firms, which systems are represented here by the firm's internal organization, often display practices reinforcing consistent themes or messages. Radically different Human Resource systems may exist because they face radically different external forces, but they also can flourish reasonably well in very similar situations, if only they are internally consistent. Consistency is obtained here because the organization is defined in terms of positions or jobs, and is directly adapted to the production technology. Human resource management aims at matching the productivity requirements of the position or the job with the productive capacities of the candidate to be employed. However, since the reward system is determined by the positional or job-productivity rather than by the individual's productivity outside this context, the productivity of some person depends crucially on the position in the firm's organization. Due to cooperation, the organization will enhance the productivity of that person drastically. Market wages on labor markets therefore refer to the potential match of some individual person with the job-productivity that may result in an organization, and are then assumed to correspond with that individual's productivity. Employment in the firm's organization creates firm-specific assets or human capital, which is controlled by the CEO. In the jargon of transaction cost economics, this feature of having all assets controlled by a single entity is called unified governance.

We have shown the impact of technological change on the organization of firms on a micro-economic level. That indirectly influences employment on a macro-economic level. Similarly, further research may determine the impact of organizational change and governance on employment. It shows how micro-economic forces can be made instrumental for macro-economic policy making.

\section{References}

Alchian, A.A., Demsetz, H.: Production, information costs, and economic organization. Am Econ Rev 62, 777-795 (1972)

Akerlof, G.: Gift exchange and efficiency wage theory: four views. Am Econ Rev Proc 74, 79-83 (1984)

Baker, G., Gibbons, R., Murphy, K.J.: Relational contracts and the theory of the firm. Q J Econ 117, 3984 (2002)

Baron, J.N., Kreps, D.M.: Strategic Human Resources. Wiley, New York (1999)

Bolton, P., Dewatripont, M.: The firm as a communication network. Q J Econ 109, 809-839 (1994)

Coleman, J.S.: Authority systems. Public Opin Q 44, 143-163 (1980)

Everett, M.G., Borgatti, S.P.: Role coloring a graph. Math Soc Sci 26, 183-188 (1991)

Garicano, L.: Hierarchies and the organization of knowledge in production. J Polit Econ 108, 874-904 (2000)

Gilles, R.P., Owen, G., van den Brink, R.: Games with permission structures: the conjunctive approach. Int J Game Theory 20, 277-293 (1992)

Gordon, D.M.: Bosses of different stripes: a cross-national perspective on monitoring and supervision. The American Economic Review, AEA Papers and Proceedings, pp. 375-379 (1994)

Grossman, S.J., Hart, O.D.: The costs and benefits of ownership: a theory of vertical and lateral integration. J Polit Econ 94, 691-719 (1986)

Harsanyi, J.C.: A bargaining model for cooperative $n$-person games. In: Tucker, A.W., Luce, R.D. (eds.) Contributions to the theory of games IV, pp. 325-355. Princeton UP, Princeton (1959)

Hart, O., Moore, J.: Property rights and the nature of the firm. J Polit Econ 98, 1119-1158 (1990)

Hart, O., Moore, J.: Foundations of incomplete contracts. Rev Econ Stud 66, 115-138 (1999) 
Ichiishi, T.: The cooperative nature of the firm. Cambridge University Press, Cambridge (1993)

Joosten, R.: Dynamics, equilibria and values. Dissertation, Maastricht University, Maastricht (1996)

Keren, M., Levhari, D.: The optimum span of control in a pure hierarchy. Manage Sci 25, 1162-1172 (1979)

Keren, M., Levhari, D.: The internal organization of the firm and the shape of average costs. Bell J Econ 14, 474-486 (1983)

Maskin, E., Tirole, J.: Unforeseen contingencies and incomplete contracts. Rev Econ Stud 66, 83-114 (1999)

Milgrom, P., Roberts, J.: The economics of modern manufacturing: technology, strategy and organization. Am Econ Rev 80, 511-528 (1994)

Pekec, A., Roberts, F.S.: The role assignment model nearly fits most social networks. Math Soc Sci 41, 275293 (2001)

Qian, Y.: Incentives and loss of control in an optimal hierarchy. Rev Econ Stud 61, 527-544 (1994)

Radner, R.: Hierarchy: the economics of managing. J Econ Lit 30, 1382-1415 (1992)

Rajan, R.G., Zingales, L.: Power in a theory of the firm. Q J Econ 113, 387-432 (1998)

Rajan, R.G., Zingales, L.: The firm as a dedicated hierarchy: A theory of the origins and growth of firms. Q J Econ 116, 805-851 (2001)

Rosen, S.: Authority, control, and the distribution of earnings. Bell J Econ 13, 311-323 (1982)

Ruys, P.H.M., van den Brink, R.: Positional abilities and rents on equilibrium wages and profits. In: Herings, J.J., van der Laan, G., Talman, A.J.J. (eds.) The Theory of Markets. North-Holland, Amsterdam, pp. 261-279 (1999)

Ruys, P.H.M., van den Brink, R., Semenov, R.: Values and governance systems. In: Ménard, C. (ed.) Institutions, Contracts, Organizations: Perspectives from New Institutional Economics, pp. 422-445. Edward Elgar Publishing Co, Northampton (2000)

Shapley, L.S.: A value for $n$-person games. In: Kuhn, H.W., Tucker, A.W. (eds.) Annals of Mathematics Studies 28 (Contributions to the Theory of Games Vol. 2), pp. 307-317. Princeton UP, Princeton (1953)

Simon, H.: Organizations and markets. J Econ Perspect 5, 25-44 (1991)

Stiglitz, J.: The efficiency wage hypothesis, surplus labour and the distribution of income in L.D.C's. Oxford Econ Papers 28, 185-207 (1976)

Teece, D.J.: Firm organization, industrial structure and technological innovation. J Econ Behav Organ 31, 193-224 (1996)

van den Brink, R.: An axiomatization of the disjunctive permission value for games with a permission structure. Int J Game Theory 26, 27-43 (1997)

van den Brink, R.: Vertical wage differences in hierarchically structured firms. Social Choice and Welfare. doi:10.1007/s00355-007-0230-7 (2007)

van den Brink, R., Gilles, R.P.: Axiomatizations of the conjunctive permission value for games with permission structures. Games Econ Behav 12, 113-126 (1996)

van den Brink, R., Gilles, R.P.: Explicit and latent authority in hierarchical organizations. Tinbergen Discussion paper 03-102/1, Free University, Amsterdam (2003)

Williamson, O.E.: Hierarchical control and optimum firm level. J Polit Econ 75, 123-138 (1967)

Yellen, J.L.: Efficiency wage models of unemployment. Am Econ Rev Proc 74, 200-205 (1984) 